\title{
CONVIVENCIA ESCOLAR, UNA MANERA DE CONSTRUIR PAZ EN LA ESCUELA A TRAVÉS DE UN MODELO DE JUSTICIA RESTAURATIVA
}

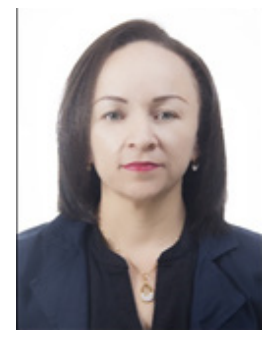

Fecha de recepción: 06/08/2019
Fecha de revisión: 05/09/2019
Fecha de aceptación: 23/10/2019

\section{RESUMEN}

La convivencia escolar como herramienta para que las personas puedan relacionarse de manera pacífica, hace uso de estrategias como la comunicación para la resolución de conflictos, donde el respeto como fuente de acción, permite una aceptación del otro tal y como es. El objetivo del presente artículo es presentar un modelo del proceso de justicia restaurativa aplicado a la escuela, donde se supere la concepción punitiva para dar paso a una visión restaurativa, que potencie la responsabilidad, la ética y los valores, y se logre promover la convivencia pacífica. La convivencia escolar implica cumplimiento de las normas que se acuerdan dentro del grupo, el trato cordial como una manera de fomentar las relaciones amistosas, y la participación dentro del grupo para así descubrir los talentos que cada uno puede aportar al desarrollo personal y social de los integrantes de la institución educativa. Este proceso requiere de acciones que permitan, no solo conciliar en los momentos de conflicto, sino reparar los daños en caso de trasgresiones, y propiciar la reflexión que se requiere para que los hechos no se repitan. Para ello la incorporación de la justicia restaurativa en la escuela, constituye un elemento que puede aportar pautas para los estudiantes, docentes, directivos, familiares, miembros de la comunidad, y también para el comité de convivencia escolar y el comité de convivencia municipal. Estas pautas abarcan la guía procesal de cada hecho, la valoración de las situaciones, el reconocimiento de las responsabilidades, la mediación como un espacio estructurado y dirigido para asistir a las partes involucradas, la socialización de los hechos, la restitución del daño causado, el monitoreo de los acuerdos, y la reconciliación con el otro, de manera que se pueda establecer una relación sin rencores.

Palabras clave: Justicia restaurativa. Convivencia escolar. Mediación en la escuela. Resolución de conflictos. Trasgresión. 


\title{
SCHOOL COEXISTENCE, A WAY TO BUILD PEACE IN SCHOOL THROUGH A MODEL OF RESTORATIVE JUSTICE
}

\begin{abstract}
The scholar coexistence as tool for people to get related in a pacific way, uses strategies as the conflicto resolution comunication, where respect as a sourse of action, allows the acceptance of the this article is to present a model of the restaurative justice process applied to the school, where the punitive visión is overcome to give space to the restaurative visión, wich enhances responsability, ethics, values an promotes the pacific coexistence. The scholar coexistence involves the filfillment of rules set by the grupo, the cordial treatment as a way to foment friendships, and the participation inside the grupo to discover the talents that each member can contribute to the personal and social development of whole educational institution. This process requieres actions wich allows, not only the conciliation on conlict moments, but repair the damages in case of transgressions, and propitiate the neccesary reflexión so these facts doesn't repeat. To get this done, the incorporation of the restaurative justice in the school establishes an element which can give rules for students, teaches, executives, relatives, comunity members and so for the scholar coexistence committee and the municipal coexistence committee. This rules include the procesal guide of each fact, situations assesment, the responsabilities admission, arbitrarion as an structured space and guided to assist the involved ones, facts socialiation, restitution of the caused damage, agreements supervision, and reconciliation with the other, so that a relationship can be stablished without grudges
\end{abstract}

Key words: Restorative justice. Scholar Coexistence. Mediation at school. Conflict resolution. Transgression.

\section{INTRODUCCIÓN}

Existen diferentes maneras de entender la justicia, y tradicionalmente una de las más utilizadas es la aplicación de sanciones. Sin embargo estas sanciones constituyen una forma de castigo para el transgresor, pero muchas veces no reparan el daño causado. La justicia restaurativa es una propuesta de cambio de paradigma, es decir, pasar de una justicia punitiva, a una justicia de diálogo y mediación a través de la restauración del conflicto por medio de acciones que permitan a la víctima sentirse retribuida, y al infractor perdonado. Eso no significa que en algunas circunstancias la acción punitiva no sea necesaria, sin embargo, para ciertas situaciones resulta mucho más educativo y eficaz aplicar un proceso de justicia restaurativa.

Los orígenes de la Justicia Restaurativa, se remontan a 1974 en Ontario; Canadá, donde se realizó el primer programa de reconciliación entre víctima y victimario. Según, García (1985), este 
programa se denominó VOM (Victim Ofender Mediation). Después de realizar varias veces este proceso, dicho programa fue ofrecido en 1978, en Indiana, Estados Unidos, y posteriormente por todo este país y por Europa.

Según lo señalado por Gutiérrez y Montoya (2007), en América Latina las iniciativas de justicia restaurativa empezaron en 1990 en Chile, Costa Rica, Brasil y México, con una variedad de prácticas de restauración. Argentina desarrolló tres procesos de negociación como son la mediación penal, la conciliación penal y la conferencia moderadora de conciliación. Brasil, por su parte se centró en la víctima, la apertura del sistema legal, y la creación de espacios de paz y tolerancia. Chile enfatizó en los mecanismos comunitarios de restauración de conflictos y proyectos de mediación en la escuela. Costa Rica incluyó prácticas de mediación y conciliación, y México aprobó la ley que establece la justicia restaurativa en el artículo 20 de su Constitución.

Históricamente, la restauración también hacía parte de la humanidad, pues dentro de algunas culturas indígenas, de distintos lugares del mundo, se aplica la reparación de un delito cometido, en Colombia por ejemplo, la justicia restaurativa está dispuesta bajo el código penal en los artículos 518 al 527, donde se especifican las definiciones, características, directrices, entre otros. Sin embargo, también existe la Conciliación en Equidad, que es similar a la justicia restaurativa pero se aplica en mayor porcentaje en las dificultades de comunidad o familia.

En el departamento de Antioquia, las facultades de Derecho junto con las facultades de Educación de algunas universidades han realizado investigaciones sobre justicia restaurativa y el enfoque apunta a la aplicación en la escuela. Dado entonces, los procesos sociales y los conflictos que se han vivido en Colombia a lo largo de su historia, la educación tiene una misión importante para cambiar las formas de relación entre las personas y enseñar a los niños a convivir de manera pacífica.

La incorporación de la justicia restaurativa en la escuela puede fortalecer los valores y las habilidades para enfrentar las situaciones que requieran una intervención constructiva, es decir, que el estudiante pueda estar en la capacidad de resolver los conflictos al utilizar herramientas como el diálogo, la tolerancia, la empatía y la restauración de hechos, además de asumir su responsabilidad en el caso para resolverlo. Este permite al trasgresor asumir la posición del afectado y a la víctima la capacidad de perdonar, aceptar una disculpa y la restauración como una manera de resolver aquello de lo cual fue afectado.

El cambio de pensamiento o procesos punitivos en situaciones escolares, debe transformarse 
en protocolos de restauración y reflexión, que lleven a la víctima y al victimario a buscar soluciones restaurativas que vayan más allá de subsanar el daño, es generar actitudes de cambio para propiciar la no repetición de hechos, sino promover en los estudiantes valores como la tolerancia, la comunicación, la solidaridad, el respeto, entre otros.

De esta manera, la transformación hacia el mejoramiento del clima escolar a través de acciones restauradoras reflexivas, muy seguramente, propiciará cambios en la escuela, que deben trascender al contexto social del que hace parte la escuela, dígase la familia y la comunidad.

\section{LA JUSTICIA RESTAURATIVA EN EL CONTEXTO ESCOLAR}

La justicia restaurativa desde el contexto escolar como lo menciona Albertí (2012), es vista como una herramienta que busca reparar un daño causado por problemas, agresiones y conflictos entre personas y que estos asuman sus responsabilidades y reconozcan los errores sin tener que culpar o castigar. Este proceso tiene unas consecuencias, reparadoras no sólo para la víctima, sino generadoras de conciencia, y de valores éticos en el transgresor. En el caso del transgresor, la reparación le llevará a:

- Asumir la responsabilidad de los propios actos

- Comprender las consecuencias de las acciones que se realizan

- Reflexionar antes de actuar, para actuar de manera más consciente

- Aprender a ponerse en el lugar del otro y generar empatía

- Reparar el error para, restituir su autoconcepto positivo, lo cual contribuirá a que se reduzcan las posibilidades de reincidencia

En el caso de la víctima, la reparación también tiene una serie de beneficios:

- Sentir que se le está haciendo justicia, que se le reconoce como víctima de la situación y que merece ser resarcido, lo cual disminuye el resentimiento y la sensación de frustración, impotencia y rabia.

- Prepararse emocionalmente para el perdón, lo cual constituye una importante liberación emocional.

- Al aceptar la reparación, se abre la posibilidad de construir nuevos vínculos y nuevas formas de relacionarse, particularmente en el caso de personas (víctima y transgresor), que están obligadas a seguir conviviendo en la escuela.

- Asumir actitudes de confianza y cordialidad, que mejoran el clima escolar.

Sin embargo, la reparación no se puede volver una constante dentro del aula de clase, es necesario llevar a los estudiantes a la reflexión para evitar cometer faltas que alteren la armonía 
del aula de clase y del contexto en general. Es decir, la restauración no puede ser vista como esa herramienta repetitiva del contexto escolar frente a hechos que alteran constantemente la convivencia, por el contrario, la restauración debe generar en cada ser humano perteneciente a la comunidad educativa la capacidad de relacionarse con el otro de manera armónica y que ante situaciones donde hayan diferencia de opiniones, estén en la capacidad de resolverla de manera pacífica valiéndose de herramientas tan sencillas como la tolerancia y el diálogo.

En la práctica docente es muy común encontrar la poca responsabilidad que tienen los estudiantes frente a hechos que han sido acusados, generalmente frente a un caso debe estar presente la víctima, el victimario y testigos que corroboren los argumentos de quien haya sido afectado, pues el victimario por lo general teme a las sanciones punitivas que hace el docente, la institución o la familia. A partir de lo anterior, es importante entonces como lo afirma Albertí (2012), desarrollar elementos claves como es la relación con el otro, vista como esa manera de reparar relaciones de forma restaurativa.

\section{PRINCIPIOS DE LA JUSTICIA RESTAURATIVA}

La práctica de justicia restaurativa en la escuela, debe estar sustentada en una visión de restauración que no necesariamente se equipara a la del derecho. En este sentido, García, Vargas y Vega (2013) consideran que la escuela se debe basar en unos principios y prácticas restaurativas que deben buscar el manejo de los conflictos como una situación de aprendizaje para toda la comunidad educativa, y debe entender, además, la dimensión humana de cada caso, y brindarle a las personas implicadas el espacio para transformar el conflicto y salir fortalecidos en valores y con habilidades para enfrentar nuevas situaciones,

Transformar el conflicto en espacios de dialogo, permite ir más allá de los hechos, porque es una oportunidad para conocer el entorno de los implicados y llegar a comprender algunas reacciones frente a las situaciones que presenta. Esto permite a quien realiza la intervención, generar espacios de aprendizaje para el manejo del conflicto.

Algunos principios que se deben tener en cuenta dentro del marco de justicia restaurativa según Ríos y Olalde (2011) son:

- Voluntariedad de las partes: Se garantiza a la víctima que no habrá ningún tipo de presión y al victimario la posibilidad de un proceso justo respetando también sus derechos, se debe entender entonces, que es un proceso al que se someten las partes de manera voluntaria sin tener ningún tipo de presión ni siquiera por quien asume el rol de mediador, de ahí, que tanto la víctima como el victimario estén en la capacidad de decidir someterse a un 
proceso de restauración.

- Gratuidad: El proceso no tiene fines lucrativos, ya que es de carácter público. En este sentido, se refiere principalmente a aquellos procesos de restauración desde el ámbito penal.

- Oficialidad: Es un proceso que debe estar dentro de las estrategias de solución de problemas dentro de la escuela, es el comité de convivencia escolar el encargado de ejecutarlo.

- Flexibilidad: Desde el punto de vista de plazos específicos para cada parte del proceso, teniendo en cuenta que debe tener cierto límite de tiempo para darle celeridad al desarrollo de la mediación, es decir, que a pesar que no se pueda ejercer presión para darle solución inmediata, tampoco se puede extender de manera tal que no se dé una solución en tiempos adecuados para ejercer la restauración.

\section{ETAPAS DEL PROCESO DE JUSTICIA RESTAURATIVA}

La justicia restaurativa requiere unas etapas para hacer uso de ella, de manera reflexiva, y se soporta siempre en el cambio de las partes para no reincidir en las faltas. Las etapas entonces incluyen también otras estrategias que dan cuenta de cada momento. A continuación se describe cada una de las etapas.

\section{Valoración}

En esta etapa se indagan los hechos, se analiza la situación, y se determina si es procedente iniciar un proceso de justicia restaurativa. Es probable que a veces no sea necesario incorporar un proceso de justicia restaurativa, pues hay casos donde existen situaciones de conflicto, pero no de violencia. Para Zapata (2015), la diferencia entre conflicto y violencia radica en que cuando hay un acto violento, este causa un daño que requiere reparación, y por tanto se puede realizar un trabajo de justicia restaurativa. Por otra parte, en los conflictos, puede haber desacuerdos, sin manifestación de violencia, de manera que el proceso más conveniente, en estos casos es la negociación para la resolución del conflicto.

Los responsables de llevar a cabo los procesos de justicia restaurativa deben identificar estos dos conceptos para poder realizar la intervención pertinente a la reparación de hechos o simplemente realizar un diálogo constructivo con las partes que simplemente se encuentren en conflicto. En este punto se corrobora si se trata de un conflicto que amerita negociación, o si el hecho donde hubo un daño, requiera reparación. Esta valoración, será de suma importancia, ya que es la que indica si se realiza un proceso restaurador o un proceso punitivo, de ahí la importancia del análisis de los hechos y la responsabilidad de realizar la intervención que mejor convenga al mejoramiento de la 
convivencia en la escuela y la reflexión de las partes.

\section{Reconocimiento}

En el reconocimiento como segunda etapa del proceso, la persona que detecta el daño da cuenta de los hechos a las personas a cargo, o a las autoridades pertinentes los hechos, se le notifica a los involucrados: se establece comunicación con el transgresor y con los afectados. Según Pérez y Zaragoza (2013), se requiere una reunión voluntaria donde se escuchan ambas partes y se establecen responsabilidades y consecuencias. Este paso es fundamental para establecer el proceso de restauración.

En esta etapa se incorporan los círculos de apoyo. Choya (2015), se refiere a éstos como el conjunto de las personas implicadas en el evento a restaurar, dígase: familia, docentes y amigos, que tienen la oportunidad de contar los hechos, expresar sus sentimientos. Esta forma de reunirse da la oportunidad de que todos los integrantes se integren y se escuchen en un nivel de equidad y oportunidad de expresión.

Es entonces el reconocimiento de las responsabilidades o culpas es el segundo momento para el proceso de restauración. Se revisa la información aportada por la victima quien necesita ser escuchada en la narración de los hechos y aporta una parte de la información, luego, el ofensor pasa a contar su versión, y es en este momento donde el transgresor reconoce su participación en los hechos y se determina su responsabilidad.

Se pretende que el ofensor reflexione sobre sus actos y que acepte su responsabilidad en los hechos. Este reconocimiento es muy importante, pues asumir el compromiso de algo que ha incidido negativamente en el otro, es quizás el paso más difícil, de ahí la importancia de que cada miembro de la comunidad educativa reconozca su participación en los hechos y se valga siempre de la verdad para poder llevar a cabo la práctica restaurativa.

El reconocimiento de las responsabilidades de las partes puede incluir que tanto la víctima como el victimario expresen no solo sus opiniones, sino, también que incluya la verbalización de sentimientos que el hecho pudo despertar en ellos, además de algunas propuestas o alternativas de solución al proceso de restauración, ayudados por la figura de un mediador.

\section{Mediación}

La mediación para Ríos y Olalde (2011), en el contexto de justicia restaurativa, trata de encontrar soluciones que induzcan a quienes están implicados a escuchar, en vez de usar la fuerza, 
a explorar los posibles arreglos en lugar de dar órdenes, a buscar soluciones que fomenten la compensación y no las represalias. Consiste hacer de una situación problema un momento de reflexión, y que se encuentre un punto intermedio que permita armonizar cualquier situación de conflicto o de violencia, para aprender de ella y buscar estrategias para que esa situación no vuelva a ocurrir.

Para llevar a cabo la mediación, se asigna un espacio de encuentro entre la víctima, el transgresor, el docente, el mediador, la familia de las partes, si se requiere, los testigos, algún experto, el comité de convivencia escolar y algunos miembros de la comunidad educativa o a quienes le competa la situación.

Se inicia con una narración de los hechos de forma más detallada. Se escucha atentamente el testimonio de las partes y/o de los testigos, y el mediador propicia un diálogo pacífico. Al respecto, Ríos y Olalde (2011) indican que la mediación es la herramienta que estimula el diálogo, invita a ponerse en el lugar del otro, a cultivar actitudes empáticas, y a asumir el grado de responsabilidad personal.

El mediador debe hacer preguntas que contribuyan a aportar los argumentos necesarios para estimar la magnitud de los daños y las consecuencias de los mismos, y sensibilicen al transgresor, para que comprenda la dimensión del hecho, y las consecuencias que este tiene en la víctima. Así mismo se propicia en la víctima una actitud de aceptación de la restauración en lugar de un castigo, que al final no soluciona el problema. Es en este punto donde se requiere cambiar la mentalidad punitiva por una visión restaurativa.

La intención de la mediación es llegar a un punto donde haya disposición para tomar decisiones que resuelvan y retribuyan, en lugar de generar castigos que producen mayor daño y que son resultado de una intención de revancha. De ahí que, este proceso mediador permite que el ser humano pueda apropiarse de la situación que se le presenta y, que además, esté en la capacidad de resolver sin necesidad de alterar la convivencia.

El acuerdo al que se llega durante la mediación implica tomar decisiones acerca de cómo se va a reparar el daño, cuánto va a durar la reparación, y bajo qué condiciones se va a hacer. Esta etapa ratifica que la reparación debe hacerse de común acuerdo, se identifican diferentes opciones de restauración, y se llega a acuerdos acerca de los más convenientes tanto el transgresor como la víctima que deberá estar de acuerdo. 
Un criterio para seleccionar la forma más conveniente de restauración es que ésta implique un aprendizaje para el trasgresor y propicie el cambio de comportamiento. También debe preparar emocionalmente a la víctima para el proceso de reconciliación y el logro de su tranquilidad personal.

Una característica de la mediación según Ríos y Olalde (2011) es la confidencialidad, de manera que el mediador debe garantizar confidencialidad de la información que se obtenga del proceso, y tener la capacidad ética de guardar reserva frente a la situación que se encuentre mediando, en lo que respecta a detalles que no ameriten ser revelados a un público mayor, pues esto puede generar malestar e inconformidad en el resto de la comunidad, y afectar el proceso de restauración.

Otra característica de la mediación es la bilateralidad, que incluye la necesidad de que las partes tengan las mismas oportunidades para expresarse, reguladas por el mediador del encuentro.

Así entonces, el proceso de mediación en la escuela debe tener en cuenta estos principios y debe partir del perfil de quien será el mediador, e incluso seleccionar el espacio donde el asunto debe llegar conclusiones y acciones reparatorias.

En esta etapa, también se asigna la figura de monitor, quien tiene la responsabilidad de hacer seguimiento, revisar que los acuerdos se estén cumpliendo y coordinar la finalización del proceso de restauración.

\section{Socialización de las decisiones}

Dar a conocer las decisiones y los acuerdos a la comunidad es la cuarta etapa del proceso. Esta socialización se puede realizar a través de reuniones de restauración o conferencias comunitarias. Este momento es importe ya que permite generar un ambiente de justicia a través de la restauración, siempre y cuando se realice una especie de culturalización y socialización al grupo social inmediato sobre este proceso de justicia restaurativa.

Es entonces sentar un precedente ante la comunidad, que dé a entender que algunos tipos de faltas implican una reparación y que no se van a pasar por alto, pero que la justicia no tiene que ser necesariamente punitiva.

En el proceso de socialización, se debe destacar que no basta intervenir con la víctima y el victimario, sino que hay que dar a conocer a la comunidad, las decisiones que se tomaron, pues es importante difundir, para crear la conciencia del pensamiento restaurativo y no punitivo en la 
comunidad.

\section{Reparación}

La reparación es, según Pérez y Zaragoza (2013), resarcir el daño ya sea material o actitudinal, sin embargo este acto debe ir más allá de reponer lo dañado, es reparar de manera significativa tanto para la víctima como para el victimario, y buscar siempre la no repetición de hechos para mejorar la armonía del entorno.

En esta quinta etapa del proceso busca que el victimario no cometa más delitos o faltas, de ahí la necesidad de generar cambios actitudinales a través de estrategias que fortalezcan la capacidad de resolver las situaciones armónicamente.

Se incorporan acciones de reeducación para el victimario, con apoyo familiar y de la comunidad, que lo lleven a observar un cambio en su comportamiento de manera positiva, y que lo conviertan en un miembro útil dentro de la comunidad. La responsabilidad de la familia en el acompañamiento en este proceso, permite asegurar que el transgresor no será reiterativo en aquellas acciones que dañen a otros, por el contrario, su entorno más cercano propiciará actitudes conciliadoras ante cualquier circunstancia.

Si la comunidad se ve involucrada en el proceso de restauración, aquellas reparaciones deben tener también un fin comunitario, que lleven al transgresor a hacer una proyección social que le permitan incluirse en su entorno, como ciudadano responsable que, con su servicio, mejore algunos aspectos de su comunidad inmediata.

La justicia restaurativa busca en la medida de lo posible que el victimario no solo repare al ofendido sino que, con otras actividades hacia otras personas, demuestre sus actitudes de cambio, y preste un servicio que permita expresar su arrepentimiento y además su actitud de cambio.

\section{Monitoreo}

La sexta etapa, consiste en hacer un seguimiento y supervisar el progreso de los acuerdos y compromisos presentados en la restitución por ambas partes, y por todo aquel que se haya comprometido al resarcimiento de los hechos.

Este proceso permite llevar un registro de cómo el proceso avanza en el cumplimiento de los acuerdos, y de la finalización de los mismos. El responsable de realizar el monitoreo es la persona que ha sido asignada durante la mediación. Si el proceso se lleva a cabo en la escuela, 
el responsable puede ser el directivo, el docente, los estudiantes o la familia, todo depende de las decisiones y acuerdos de la restauración. Al final el monitor debe informar, por escrito, si los acuerdos se llevaron a cabo y cómo se desarrolló el proceso

\section{Reconciliación}

Por último y séptima etapa, está la reconciliación, que implica la creación de canales de comunicación y trato cordial, así como aprendizaje de la tolerancia. La reconciliación es una alternativa para vivir en paz, sin rencores o rencillas con el otro. Es la capacidad de perdonar y saber que no existen sentimientos negativos hacia el otro, sin necesariamente tener lazos de amistad. Consiste en restaurar una relación que permita la convivencia pacífica después de un conflicto.

El perdón puede definirse, según Lillo (2014) como aquella acción que está contenida en el proceso de reconciliación, mientras que la reconciliación no está incluida en el perdón. Después de una agresión, la relación no puede volver a ser la misma, porque ya no existe o está muy dañada, y en muchos casos es necesario reconstruir la relación o cambiar los términos en los que ésta se da. Esto implica un cambio de actitud, tanto por parte del transgresor, como por parte de la víctima.

La reconciliación en justicia restaurativa se enfoca entonces en la capacidad que tenga la persona de restaurar una relación sana después de un conflicto o un acto de violencia, lo cual contribuye significativamente a una convivencia pacífica dentro y fuera de la escuela.

En este punto del proceso restaurativo, el transgresor completa las acciones reparadoras cuando no solo restituye los daños, sino que hay una aceptación dentro de la comunidad, se visualizan actitudes reflexivas que permiten el mejoramiento de sus acciones, genera sentimientos de confianza y cuando sus relaciones se tornan pacificas con el otro.

\section{POSIBLES OBSTÁCULOS O LIMITACIONES DE LA JUSTICIA RESTAURATIVA}

\section{EN LA ESCUELA:}

En el momento de implementar la justicia restaurativa en la escuela, es posible encontrar personas que aún tienen la idea de la sanción punitiva como alternativa para mejorar la convivencia. Esta forma de pensar puede ser exclusiva de alguna persona, o estar generalizada en los miembros de la comunidad educativa. Desde allí, aparecen algunas limitaciones para el proceso de justicia restaurativa, por lo que se debe generar una reflexión acerca de esta estrategia en la escuela, como una herramienta que permitiría generar en los estudiantes alternativas de sanación, restauración y relación. 
Otras dificultades que podrían presentarse son: que el victimario no muestre arrepentimiento, la no aceptación de la restauración por parte de la víctima, la falta de interés o disponibilidad de los miembros de la escuela, y la actitud del comité de convivencia para llevar a cabo el proceso

También, es común encontrar en la escuela a docentes, que por su quehacer cotidiano, son los mediadores y monitores de muchas situaciones que ocurren dentro y fuera del aula de clase, sin embargo su rol mediador no es el más oportuno para llevar a cabo este proceso, pues se comete error de hacer la reparación públicamente, de manera unilateral y sin mediación. En ese caso la acción reparatoria es inducida, y vista como la manera de reponer materialmente el daño, pero se omiten principios como la voluntariedad, la confidencialidad y la bilateralidad.

\section{CONCLUSIONES}

La justicia restaurativa en la escuela hasta ahora presenta nociones de aplicabilidad, pero es necesario profundizar sobre el tema y concientizar a la comunidad educativa en cuanto a que ésta representa una oportunidad de reinserción y de crecimiento personal. La justicia restaurativa fomenta la reflexión individual para la no repetición de los hechos, y puede generar en los seres humanos valores universales como la amistad, amor, bondad, confianza, fraternidad, honor, justicia, honradez, libertad, paz, respeto, responsabilidad, solidaridad, tolerancia, valentía y verdad.

\section{BIBLIOGRAFÍA}

- Albertí, Mónica. (2012). Hacia una escuela justa: De la incorporación de la justicia restaurativa en el ámbito escolar. Colegi de Pedagogs de Catalunya. P 1-3. publicado el 01 de septiembre de 2012. Barcelona.

- Brenes, Carlos. (2009). Justicia Restaurativa Una herramienta para la solución al fenómeno de la criminalidad costarricense. Licenciatura en Derecho. Universidad Fidélitas. Costa Rica

- Choya, N. (2015). Prácticas restaurativas: Círculos y Conferencias. Revista Pensamiento Penal. (Pp 1-50). Publicado el 29 de julio de 2015.

- Daza, A. (2014). Sentido de pertenencia. Documento en línea. Disponible en: www. aporrea.org. Consulta: 20/10/2018.

- Espinosa, I. Ojeda, P. Pinillo, Loreto. y Segura, S. Convivencia escolar en una escuela básica municipal de la reina. Conocimiento de su manual de convivencia: Un estudio de caso. Magister en Dirección y Liderazgo para la Gestión Educacional. Universidad Andrés Bello. Chile

- García, M. (1985). La Mediación Penal y el Nuevo Modelo de Justicia Restaurativa. 
Revista Internacional de Doctrina y Jurisprudencia. https:/w3.ual.es/revistas/ RevistaInternacionaldeDoctrinayJurisprudencia/pdfs/2014-09/articulos-mediacion_ penal.pdf. Fecha de consulta: 19/08/2018

- García, R. Vargas, D. y Vega, N. (2013). Bases para la aplicación de una justicia restaurativa en el contexto escolar. Revista Folios de Humanidades y Pedagogías. No 1.(Pp 89-98). publicado el 12 de diciembre de 2013.

- Gutiérrez, L. y Montoya, J. (2007). Una aproximación a su teoría y aplicación en el sistema jurídico colombiano. Título de Abogado. Universidad de Manizales. Colombia

- Lillo, J. (2017). Sobre el Perdón y la Reconciliación: Una perspectiva psicoanalítica. Temas de Psicoanálisis. No 7. (Pp 1-35). Publicado enero de 2013.

- Pérez, J. y Zaragoza, J. (2013).Justicia Restaurativa: Del castigo a la reparación. México. Editorial Universidad Nacional Autónoma de México.

- Pulido, R. Martín, G. y Lucas, B. (2013). Orígenes de los Programas de Mediación Escolar: Distintos enfoques que influyen en esta práctica restaurativa. Scielo. Volumen 29, No 2.

- Ríos, C. y Olalde, A. (2011). Justicia restaurativa y mediación. Postulados para el abordaje de su concepto final. Revista de mediación. ADR, Análisis y Resolución de Conflictos. Volumen 11, Año 4, No 8. (Pp 10-19). Publicado segundo semestre del 2011 